\title{
Transparency and imagining seeing
}

\author{
Fabian Dorsch* \\ Department of Philosophy, University of California, Berkeley,
}

USA

\begin{abstract}
In his paper, The Transparency of Experience, M.G.F. Martin has put forward a wellknown - though not always equally well understood - argument for the disjunctivist, and against the intentional, approach to perceptual experiences. In this article, I intend to do four things: (i) to present the details of Martin's complex argument; (ii) to defend its soundness against orthodox intentionalism; (iii) to show how Martin's argument speaks as much in favour of experiential intentionalism as it speaks in favour of disjunctivism; and (iv) to argue that there is a related reason to prefer experiential intentionalism over Martin's version of disjunctivism.
\end{abstract}

Keywords: disjunctivism; hallucinations; imagination; intentionalism; object awareness; perception; transparency; visualising

One of the most powerful arguments against intentionalism and in favour of disjunctivism about perceptual experiences has been formulated by M.G.F. Martin in his paper The Trans-parency of Experience. The overall structure of this argument may be stated in the form of a triad of claims which are jointly inconsistent. ${ }^{1}$

(i) As reflection on the phenomenal character of visualising an external thing reveals, it is not neutral about the presence of the visualised thing in the imagined situation.

(ii) At least in some cases, visualising an external thing consists in imagining a visual perception of it.

(iii) But imagining a visual perception of an external thing is neutral about the latter's presence in the imagined situation.

Given that visualising cannot be non-neutral and identical with a neutral form of imagining at the same time, one of the three claims has to go. Martin presents detailed argu-ments in favour of (i) and (ii) and concludes that we should give up (iii). Intentionalists, on the other hand, typically attack (i) or (ii), while holding on to (iii). In this paper, I would like to suggest that the intentionalist response gets its target wrong: instead of trying to under-mine one of the first two claims, it should instead raise doubts about the last. In particular, I argue that intentionalism has the resources to ensure and explain the non-neutrality involved in imagining and perceiving something.

Much of the paper will be concerned with a reconstruction of Martin's complex argu-ment. Intentionalists have been misunderstanding key steps in his line of reasoning, so that

*Email: fabian.dorsch@uclmail.net 
it is worthwhile to explore where they went wrong, and why the challenge raised by Martin is real. The resulting formulation of the argument against intentionalism may very well be more mine than Martin's. My goal is not to provide a scholarly introduction to Martin's writings, but instead to make his case against intentionalism as strong as possible. Having a detailed look at the problems which visualising poses for theories of perceptual experience makes it possible to find a satisfactory response on behalf of intentionalism. Indeed, it will turn out that some aspects of visualising thereby discovered actually favour intentionalism over disjunctivism.

The version of intentionalism to be defended here differs significantly from those currently en vogue - most notably in linking intentionality essentially to consciousness, and in assuming a self-presentational (i.e. experiential and self-reflexive) element as part of perceptual (and other kinds of) intentionality. ${ }^{2}$ It may therefore be aptly labelled experiential intentionalism. Much of the paper will be devoted to showing that, while many current versions of intentionalism cannot provide a satisfactory answer to Martin's challenge, experiential intentionalism can do so. Experiential intentionalism is thus to be preferred, not only over disjunctivism, but also over other versions of intentionalism.

In the first section, I introduce the intentionalist and the disjunctivist approaches to perceptual experience and contrast their distinct accounts of the transparency and nonneutrality of perceptions. ${ }^{3}$ The next three sections elaborate on why we should accept the claims (i) and (ii), respectively, and why intentionalists have been misguided in rejecting them. In particular, the nature of experiential imagination - that is, imagining an experience - and that of imaginative projects involving the former are considered in detail. The fifth section is intended to illustrate why current forms of intentionalism cannot avoid the challenge posed by Martin's argument for thesis (iii). It also aims to illustrate how both disjunctivism and experiential intentionalism can do better, especially with respect to an explanation of the transparency and non-neutrality of visualising. In the final section, I use the previous discussions about what it means to imagine having a perceptual experience in order to formulate an objection against disjunctivism. I conclude with some remarks about the fact that experiential imagination seems to involve two different objects of awareness, namely the imagined experience and the latter's own object.

\section{Intentionalism and disjunctivism}

Intentionalism and disjunctivism disagree about the nature of perceptual experience. That is, they put forward different accounts of the first-personal side of our perceptual awareness of external things and their features. But they do so before a background of common assumptions and observations. One is that perceptual awareness differs from propositional thought in showing us objects, rather than describing, naming or indexing them. This contrast is not restricted to the realm of the mental. It also characterises the difference between, say, pictures and sentences. Another, closely related shared observation is that perceptions are not merely about objects, but take them to be a certain way: they are non-neutral about how things are. This aspect distinguishes perceptions, for instance, from desires which may also be directed at objects, but do not involve a claim about how they are. ${ }^{4}$ And finally, both parties agree that perceptions are immediate in that they present their objects as part of our actual environment. That is, their non-neutrality concerns the actual presence of things before our senses. This perceptual commitment about how things actually are is reflected in the fact that perceptions enjoy epistemic authority over our beliefs about our actual environment. Furthermore, the non-neutrality of perceptions is salient from the firstperson perspective, as part of their transparency. Perceptions are transparent insofar as 
introspective attention to them reveals the external things and features of which they make us aware, and no other candidate objects of awareness (such as sense-data or mental pictures). The positive element of this aspect of the phenomenal character of perceptions - of what perceptions are like for the subject - consists in their non-neutrality: when attending to our perceptions, we find objects that are given to us as part of our actual environment.

However, intentionalism and disjunctivism provide different theories of how perceptions relate us to external things, and of why they are non-neutral and immediate. Intentionalism about perceptual experiences does not distinguish between perceptions and hallucinations when addressing these issues. It maintains that perceptual experiences whether they are veridical or not - make us intentionally aware of those entities. Accordingly, they are understood as presenting us with external objects without requiring their existence. They are non-relational appearances of things which do not involve the latter as their constituents. Moreover, intentionalism characterises the form of intentionality common to both perceptions and hallucinations as distinctively perceptual. This means that they involve a specific intentional attitude towards their objects which takes the latter to be actually present before us. This explains why they are committal to aspects of our actual environment, and why they have authority over our respective beliefs. ${ }^{5}$ Given that perceptions and hallucinations are said not to differ in respect of how they make us subjectively aware of things, intentionalism concludes that they share the same phenomenal character and are therefore of the same fundamental kind of experience. ${ }^{6}$

By contrast, disjunctivism about perceptual experiences (as it is defended by Martin) maintains that there is an essential difference between the character of perceptions and the character of hallucinations, to the effect that they belong to different fundamental kinds of experience. The difference in question is that, while perceptions make us relationally aware of objects, hallucinations do not. ${ }^{7}$ That perceptual awareness is relational means that the character of perceptions - and thus the perceptions themselves - are constituted by the external objects of which they make us aware. This explains why we find those objects when reflecting on our perceptions, and also why the latter are non-neutral about the presence of the former in the situation before our senses.

Intentionalism and disjunctivism, so defined, are incompatible with each other. They provide rival accounts of how perceptual experiences make us aware of objects and which character(s) they show. And they give different answers to the question of whether perceptions and hallucinations belong to the same fundamental kind of experience. Nonetheless, it will become important in the last two sections that intentionalism can endorse - if not in fact, then at least in spirit - some of the central ideas of disjunctivism, such as the priority of perceptions over hallucinations.

In particular, it may be argued that perceptual experiences do not only have a firstpersonal side to them, but also a third-personal side. The disjunctivist position considered so far has been concerned with how to conceive of perceptual object awareness - that is, of how it is for the conscious mind to be presented with objects. But when we are perceiving something, we also stand in interesting causal or similar relations to the world, which are missing in the case of hallucination and which can be investigated from the perspective of the natural and cognitive sciences. It is surely not uncontroversial whether these thirdpersonally accessible, structural features of our cognition of objects should really figure in an account of the nature of our predominantly first-personal experience of objects. But the two phenomena are clearly related (e.g. we can influence our perceptual awareness of things by influencing our structural relation to the world). In particular, if there is indeed a difference in character between perceptions and hallucinations, it is very likely 
to be due to some structural difference between cases in which we perceive something and cases in which we hallucinate something. That is, it should be expected that any constitutional difference between the two kinds of perceptual experience is accompanied by and perhaps also partly derivable from - a difference in some causal or similar element.

This leaves room for a version of intentionalism which, despite claiming that perceptions and hallucinations possess the same character, accepts that the two differ structurally - perhaps even essentially so. In this way, intentionalism can accommodate the (fairly) uncontroversial idea that, while some intentional experiences (i.e. perceptions) relate us to the world, others (i.e. hallucinations) do not. It just takes the relation in question to be, not a relation of awareness, but some other kind of relation that is accessible to empirical investigation. If we label the view that perceptions and hallucinations differ also in character phenomenal (or naive realist) disjunctivism, and the view that they differ merely in structure structural disjunctivism, then we can say that intentionalism is compatible with the structural variant of disjunctivism, but not with the phenomenal one. Intentionalism can accordingly even assume that perceptions and hallucinations differ in nature namely in their third-personal side. However, if not stated otherwise, my focus in what follows will be on the phenomenal version of disjunctivism. And I will understand intentionalism as being neutral on the issue of whether the structural difference between perceptions and hallucinations amounts to a difference in nature.

\section{The transparency of visualising}

Perceptual awareness is not the only form of object awareness which is transparent and committal. Imaginative experiences - and, notably, visualising - possess both features as well (Martin 2003, 413ff.). ${ }^{8}$ Most of all, episodes of visualising, too, enjoy some kind of epistemic authority over our beliefs - this time only over our beliefs about what is part of the imagined situations. It makes sense to ask which entities are part of the possible situation that we are visualising at a given moment. And our answer should be influenced by what we are visualising, given that the latter typically determines what is contained in the imagined world. Other things equal, if it is a green tree that we are visualising, then there is a green tree in the situation that we are imagining. Hence, picking up on what we are visualising should guide us in forming beliefs about what is part of the respective imagined situation. This authority of visualising over our beliefs about the imagined world may be countered, or perhaps need not always be present. For instance, we may visualise a green tree simply as part of imagining having a hallucination of a green tree, in which case we should not believe that there is a 'hallucinated' green tree in the imagined world, but at best that there is a hallucinatory experience as of such a tree.

The epistemic dimension of visualising becomes important in cases where we are using visualising to acquire knowledge - say, about possibilities or conditional truths. ${ }^{9}$ In his most recent book, Timothy Williamson argues that visualising is one of the many empirical capacities that we may employ in order to acquire modal knowledge - or, in his concrete example, knowledge of some conditional, which forms the first step to modal knowledge. Considering a situation in the mountains, he describes the largely non-inferential process involved in coming to know that a certain rock would have landed in a lake, if its path had not been blocked by a bush:

You notice one rock slide into a bush. You wonder where it would have ended if the bush had not been there. A natural way to answer the question is by visualizing the rock sliding without the bush there, then bouncing down the slope. You thereby come to know this counterfactual: 
[...] If the bush had not been there, the rock would have ended in the lake. (Williamson 2008, 42)

Acquiring knowledge in this way is possible only if, by visualising the rock, the slope and the lake, we take them all to be part of the same possible situation. And this requires that our episode of imagining is committed to their existence in that situation. Two things need to be noted about this commitment. The first has already been hinted at: it is not trivial to claim that the visualised object is part of the imagined situation. The example of a desire for something (e.g. an ice-cream) shows that there can be mental states which are object-directed, but do not take a stance on how things are in a certain world. ${ }^{10}$

The second point to consider is that the non-neutrality linked to visualising cannot be external to it, that is, derive from its further intellectual context rather than from the basic episode of visualising itself. The distinction between the episode and its context is not meant to deny that simple instances of visualising - or 'images', if one prefers may include intellectual or other non-sensory elements (e.g. the presentation of objects as mind-dependent or -independent). An episode of visualising differs from the additional thoughts in two other respects, namely that the former is an instance of object awareness, and that it may occur without the latter - although it may also form a more complex imaginative project with them. Now, that we end up being committed to the presence of what is visualised in the imagined situation is due to the fact that visualising itself is committal in this way. That visualising presents us with, say, a green tree is not neutral on whether there is such a green tree in the imagined world (rather than, say, a yellow flower, or no such object at all). We may cancel out this commitment by adding the thought that, within the imagined world, the green tree is merely hallucinated and therefore not really part of that world. But, as a default, visualising takes the visualised object to be part of the imagined situation.

If it were instead neutral on this issue, the commitment would have to come from some additional thought specifying that the imagined situation indeed contains whatever is visualised. The green tree would become part of the imagined world, not by being visualised, but instead by being thought to be part of that world. This is in fact, roughly, the view suggested by Burge as an alternative to the disjunctivist's take on visual experience. For him, the commitment to the presence of the visualised object - or, in the case of visualising an external thing by imagining a perception of it, the veridicality of the latter - in the imagined world comes not with the basic episode of visualising, but instead with a suppositional thought accompanying the first. Note, however, that Burge uses the term 'visualizing' to denote the complex and committal imaginative project which contains not only the simple visual presentation or image, but also the additional supposition:

[One begins] with the supposition of veridicality. One simply takes the content of the imagined experience to be veridical. [...] I hold that the imagery does not by itself guarantee the presence of the imagined scene [...]. What gives us the imagined scene is the fact that we are visualizing the scene. [...] The imagined veridicality is not derivative from the imagery itself. Visualizing something with a given imagery has do to with how the imagery is used. (Burge 2005, 65ff.)

But this alternative picture would not be able to pay justice to the character of visualising (Martin 2003, 416ff.). To get clearer about this, consider the issue of what a neutral visual presentation of an object would have to be like. When we are looking from a distance at a perfect wax replica of a friend of ours and are completely in the grip of its illusionary effect, it seems to us as if there really is our friend before us. That is, our visual experience is 
committed to the presence of our friend in our environment, and we are bound to form the respective belief. However, when we move closer to the figure and come to recognise it as being just a wax replica, how things appear to us alters substantially. Now, it seems to us as if there is a wax figure in front of us, and our experience commits us to accept its actual existence before our eyes. Relatedly, although we continue to enjoy some kind of awareness of our friend, our experience has stopped being non-neutral about his presence. So here we have a case of visual object awareness, which in some sense is still about a particular object, but which does not commit us to its presence in our actual environment. This neutrality, however, has been gained by a change in the object of awareness. We are now presented with a three-dimensional depiction of our friend, rather than with our friend himself. Indeed, when introspecting our experience, we find the wax figure and its pictorial properties, but no human being. This explains why we are committal with respect to the former, but not with respect to the latter.

In line with these considerations, if visualising were neutral about the presence of the visualised object in the imagined situation, we should expect not to find that object, but instead some substitute - such as an internal picture - when reflecting on our imaginative experience. But this does not seem to be the case. When we introspect an episode of visualising, what is revealed to us is the visualised object, and no other candidate object of awareness. In other words, visualising is transparent, just like seeing is. The two kinds of visual experience differ in their immediacy: while an episode of seeing presents its object as actually being there before us, visualising does not do this, but instead locates the object in the imagined situation. There is, hence, good reason to accept the first claim in the triad introduced at the beginning. As part of its transparent nature, visualising an external thing is by default committed to the latter's presence in the imagined situation. And this commitment remains intact, as long as it is not cancelled out by some additional intellectual stipulations about what is in fact imagined.

\section{Visualising as imagining seeing}

The second claim of the triad maintains that some instances of visualising an external thing amount to instances of imagining a perception of such a thing. It is a special case of Martin's Dependency Thesis: ${ }^{11}$

[T]o imagine sensorily a $\varphi$ is to imagine experiencing a $\varphi$ [.]. (Martin 2003, 404)

Imagining a perception - or, more generally, experiential imagination - is a case of object awareness, just as much as seeing or visualising an external thing is. What we are aware of when imagining an experience is just that, some experience. More specifically, we are aware of the first-personal side of an experience, that is, of its phenomenal character. We imagine some experience by imagining some instantiation of its character. Its third-personal side (if experiences have any) is, so to speak, 'invisible' to object-directed imagining. Of course, we can have additional thoughts about it. But it is not presented as part of a case of imagining with an experience as its object. The reason for this is that this form of imagining is experiential, in the same sense in which seeing and visualising are visual. Just as the latter are limited to the presentation of visible entities, experiential imagining is restricted to the presentation of phenomenal aspects of mental episodes. The latter's structural features lack an 'experiential appearance', so to speak. Again, experiential awareness does not differ in this respect from, say, visual awareness. When we see or visualise a lemon, we see or visualise its visual appearance, but not its biological nature, for example. 
Intentionalists typically select the Dependency Thesis - and therefore also claim (ii) as the main target of their criticism of Martin's argument against intentionalism. Indeed, if imaginative experience is to be understood in the same intentional terms as perceptual experience, it is difficult to understand why, say, seeing and visualising should not make us aware of the same objects, namely external things. If perception does not involve an awareness of an experience, why should imagination do so, if both are assumed to involve the same kind of object awareness? This doubt should be taken serious - not the least because it simply confirms that there is in fact a tension between the intentionalist thesis and the claim (ii). While Martin draws the conclusion that the former should be given up, it is also very plausible to question the latter.

Some of the intentionalist objections, however, seem to have misunderstood the intended scope or nature of the claim at issue. ${ }^{12} \mathrm{~A}$ first point to be noted is that that thesis (ii) need not have universal application for the argument against intentionalism to go through. For this purpose, it is meant to be the claim that some cases are instances of experiential imagining - and not the claim that this is true of all. More is not required for the argument against intentionalism under consideration issue here. And more is also not intended by Martin, or supported by his line of reasoning in favour of (ii) (Martin 2003, 404ff.). ${ }^{13}$

Another important issue is that this argument concentrates on, and exploits the special features of, cases in which our episodes of visualising involve certain subjective properties. Subjective properties are characterised by the fact that they are experience-dependent: their instantiation is dependent on the occurrence of a specific experience. Martin's focus is on cases in which instances of visualising involve a certain kind of perspectivalness; and thesis (ii) should be understood as being restricted to those cases (or to similar cases, such as imaginative experiences involving aspects of painfulness or itchiness). ${ }^{14}$ What (ii) therefore claims is that visualising is identical with imagining perceiving when it involves the subjective perspectival element at issue.

By perceiving an object, we may acquire knowledge about the latter's specific spatial location. But our perception does not thereby place the object in objective space. When we look at a building that is located roughly to the South-East of the bench on which we are currently sitting, we do not see it as being to the South-East of that bench. In particular, we do not perceive objects as being orientated in accordance with the cardinal directions. Instead, we see them as being orientated towards ourselves - for instance, we see the building as being to our left. What this means is that we perceive objects as part of egocentric space, and not as part of objective (or 'absolute') space. ${ }^{15}$ One manifestation of this fact is that our perception of the building inclines and entitles us to judge that it is to our actual left, but not that it is to the South-East of the bench. Coming to know the latter requires additional information - notably about our own location and orientation in objective space (Campbell 1995).

Nonetheless, our perceptions of egocentric locations are still as much concerned with actual space as is our knowledge of objective locations. We see the building as being to our actual left, as part of our actual environment. If this were not so, our experience would not be able to provide us with all the information necessary to properly interact with what we see - for example, to succeed in walking over to the actual building. But that perception does provide us with this information is illustrated by the fact that such interaction does not require inferring the presence of the building to our actual left from perceiving it as being to our left and believing that such experiences are (typically) concerned with the actual world. The issue of which world our perceptions are concerned with simply does not arise - it is our world, the world in which we perceive. Something similar is true of the 
temporal relevance of our perceptions: they concern our present environment. We see the building as presently being to our left, and not as having been there in the past, or as going to be there in the future. ${ }^{16}$

Part of our perception of the building as being to our actual left is implicit, however. We do not explicitly experience ourselves and our spatial relation to the building when perceiving the latter. We are not among the entities presented to us by our experience. Of course, we can see other perceivers - and even ourselves, say, by utilising a mirror or some similar apparatus which turns us into the object of our own perceptions. But normally, when we are simply subjects of perception and perceive the orientation of objects relative to us, we do not see us, but only the objects. Our own perspective is only implicitly reflected in our perceptual experiences, namely as the point of view orientated to which objects are presented to us. As a consequence, what figures explicitly in our experience is not the relational property of being to the left of us, but the monadic quality of being leftish.

It seems that such a quality can figure in perception in two different ways. The perceptual experience may instantiate the quality; or it may instead present an external object as having that quality. In both cases, this has consequences for the phenomenal character of the experience concerned. In the first case, the quality constitutes one of the non-presentational aspects of that character. In the second case, it is a constituent of one of the character's presentational aspects. ${ }^{17}$ That the quality of leftishness figures in our perception of the building therefore means that the latter instantiates a certain character aspect - either a non-presentational aspect, or the presentational aspect of presenting the building as being the monadic property of being to the left. ${ }^{18}$

Which view is to be preferred in the end does not matter here. Indeed, it is not so clear whether they actually differ in any substantial way - which might explain why Martin appears to switch between both views in some of his formulations (e.g. when talking about the quality of itchiness). The step from acknowledging the presence of a non-presentational aspect of the character of a perception to projecting this aspect onto the perceived object is indeed small - as discussions about blur or similar phenomena illustrate (Peacocke 1983; Dorsch and Soldati forthcoming). Moreover, any presentation of something as being leftish would lack the status and force of the presentation of it as being to our actual and present left. In particular, we do not see the building as having the monadic property of being to the left; and we are not inclined or entitled to believe it to genuinely instantiate this property. Of course, we may say 'the building is to the left'. But when prompted, we will happily clarify that what we really meant was that it is to the left of us.

In any case, that the character of our perception of the building includes this phenomenal aspect - let us call it the aspect of leftishness - should not be doubted. We can attend to it; and we can exploit it when drawing a picture of how the building looks like when seen from our current point of view. That is, we can depict an object as being to our actual left by drawing it on the left side of the canvas - instead of, say, by drawing both ourselves and the object. $^{19}$

But how is the instantiation of the aspect of leftishness linked to the perception of the property of something as being at some specific location to our actual left? More generally, how does the perspectivalness of an experience relate to the determination of what is experienced? Martin's insightful observation is that the former suffices for the latter (Martin 2003, 410). If an experience of an object exemplifies leftishness - that is, shows a respective non-presentational phenomenal aspect or, alternatively, presents the object as being to the left - then it is an experience of the object as being to our actual left. More specifically, the presence of the perspectival aspect of leftishness is sufficient to ensure, first, that the experience concerned is an experience of something as being to our left (rather than to 
our right) and, second, that it is an experience of something as being to our actual left (rather than to our left in a merely possible situation). Indeed, Martin claims even more, namely that it also suffices for having a perceptual experience of something as being to our actual left. This makes sense since the other two kinds of visual experience, which may involve the aspect of leftishness, are not - or at least not in their simplest forms - concerned with our current environment. Episodes of visualising present objects as part of imagined situations (cf. below), while episodes of visual memory present objects as part of past situations. I return below to the issue of how important this additional claim is for Martin's argument.

That the instantiation of the aspect of leftishness turns the respective experience into an experience of something to our actual left is a direct consequence of the implicitness involved in our perception of the spatial relations that objects bear to us in egocentric space. As noted above, we see objects as being to our actual left (and not, say, as being at an egocentric location in some merely possible space). But this relational property is typically not explicitly given to us. Instead, what figures in our experience is solely the monadic quality of leftishness. Hence, we perceive the instantiation of the property of being to our actual left simply by being aware of the quality of leftishness. When we see the building as being to our actual left, no aspect of our perception but its aspect of leftishness plays a role in determining that we experience the building at that specific location in our actual environment. If the aspect of leftishness is taken to be presentational, this thought becomes even more straightforward: our perception presents the building as being to our actual left just by presenting it as being to the left; no other presentational element is needed or involved. What we are confronted with here is the particular subjectivity of the aspect of leftishness. Its actual instantiation is both necessary and sufficient for the experience of something as being to our actual left. ${ }^{20}$

However, as Martin notes, these considerations about perception give rise to a puzzle in the case of visualising (Martin 2003, 410). On the one hand, our episodes of visualising involve the same kind of perspectivalness as our episodes of seeing (Hopkins 1998, chap. 7). We visualise buildings as being to the left of certain subjective points of view. And we normally do so without explicitly presenting those points of view or any subjects occupying them. What figures in our respective imaginative experiences is therefore, again, the monadic quality of leftishness, and not the relational property of being to the left of some subject in the subject's environment. But this means that our episodes of visualising may involve the same phenomenal aspect of leftishness as our episodes of seeing. Indeed, this is partly due to the relative simplicity of our visual presentation of the egocentric orientations of objects. It is devoid of any explicit reference to the subject of experience and, therefore, allows us to visualise something as being to the left without thereby visualising it as being to the left of any particular subject.

On the other hand, when visualising buildings as being to the left of subjective points of views, we need not - and typically do not - imagine them as being to our actual left. At least in the simplest cases, our episodes of visualising do not locate their objects in our actual environment, but instead in some imagined space (Wittgenstein 1984, 622 and 628; Sartre 2004, 8ff.). ${ }^{21}$ Of course, we can project our image onto our actual environment by taking what we imagine to be part of actual space. But even then, there is no real competition between what we see and what we visualise. For example, when looking at a certain picture on our kitchen wall, we may visualise with open eyes how things would look if there were a different picture at the same spot on the wall. But such a complex and mixed presentation does not amount to a presentation of the impossible state of affairs of two pictures occupying the same part of space. 
So, episodes of visualising may involve the aspect of leftishness without presenting something as being to our actual left. But due to the subjectivity of the aspect of leftishness noted above, its instantiation is inseparably linked to the presentation of something as possessing the relational property of being to our actual left. Hence, the instances of visualising concerned cannot exemplify the aspect of leftishness. This raises the question of how it is involved in visualising instead. Martin's proposal is that, in visualising, we imagine an experience as instantiating the aspect of leftishness - that is, we imagine a perspectival experience of something as being to the left in the imagined situation. When we visualise a building as being to the left, our imaginative episode does not instantiate the aspect of leftishness. But it still involves the latter by representing another experience as instantiating it.

The proposal captures the specific subjectivity of the aspect of leftishness. For it takes the instantiation of that aspect in a certain world to be sufficient for the occurrence of an experience of something as being located to the experiencing subject's left in that very same world. Actual perspectival experiences concern actual space, while imagined perspectival experiences concern imagined space. Moreover, what needs to be imagined is a perceptual experience. As noted above, other perspectival experiences are not concerned with the current state of the world in which they themselves occur. Instead, they are concerned with the past of that world (as in the case of visual recall), or with an entirely different possible world (as in the case of visualising). Hence, neither episodic memories, nor imaginative episodes can instantiate the subjective aspect of leftishness. If we want to imagine an experience with that aspect, we therefore have to imagine a perspectival perception. This conclusion can also be inferred more directly from Martin's additional claim mentioned above, namely that the presence of leftishness suffices for the presence of perception. Indeed, the reasoning put forward in support of that claim has been very similar to the one rehearsed in the second half of this paragraph. But, strictly speaking, the additional claim does not seem to be necessary for Martin's argument.

Martin further illustrates this argument by comparing the subjective perspectivalness of perceptions to the subjective aspects involved in some bodily sensations. His example are experiences of itchiness; but experiences of pain are equally good candidates. Experiences of pain instantiate the phenomenal aspect of painfulness: they are feelings of pain. Moreover, having a feeling of pain is sufficient for there actually being a pain and, hence, for experiencing an actual pain. If we feel pain in a certain part of our leg, then that part of our leg does indeed hurt - independently of whether its skin tissue is damaged, say. ${ }^{22}$ By contrast, merely imagining our leg as hurting does not involve the presentation of an actual pain in our leg. But this raises, again, the question of how imagining a pain can still involve the aspect of painfulness - which it clearly does, albeit possibly to a lesser degree of intensity and determinacy than real feelings of pain. As above, the solution is to understand imagining a pain as imagining a sensation of pain - that is, as imagining an experience which instantiates the phenomenal aspect of painfulness.

This concludes what are, in essence, Martin's considerations in favour of the thesis (ii). However, the analogy with pain suggests a second route to the conclusion that visualising the orientation of objects in egocentric space requires imagining perceiving that orientation. Feeling a pain is not only sufficient for the existence of pain, it is also necessary for the latter. Our leg does not really hurt if we do not feel pain. Of course, other things may distract us so that we do not always notice the pain. But if we do not feel any pain in our leg, despite being sufficiently attentive to the latter, it does not seem true to say that our leg in fact hurt. In particular, bystanders cannot insist that we are in pain by pointing to some bodily damage to our leg. Such evidence cannot trump our failure to feel pain. Accordingly, the 
instantiation of pain requires an experience of that pain - and, presumably, as part of the same world. Hence, imagining a pain has to involve imagining feeling that pain.

Now, egocentric orientational properties seem to be similarly subjective - opening up the possibility of formulating a similar argument in favour of the Dependency Thesis. Martin does not discuss this second route to the conclusion; and it is not clear whether he would accept the subjectivity of egocentric orientations, or the argument exploiting it. But even if not, it is still worthwhile to discuss both. When we see a building as being to our left, it does not possess this orientation independently of being perceived by us as having it. Certainly, the objective location of the building comes with the disposition of giving rise to a perception of leftishness when viewed from a position to its North-West by a normal human being with a normal orientation in objective space (e.g. standing on his feet, etc.) who faces South. But its perceived property of being to our left cannot simply be reduced to this objective disposition. Instead, the instantiation of this egocentric orientation seems to depend on our actual perceptual awareness of it.

For one thing, which dispositional property is correlated to the property of being to the left of us varies with changes in our location in objective space. Once we begin to move or turn around, the building may very well cease to be to our left - though it may also begin to be to the left of another person who steps in and takes our previous spot. The disposition may therefore constitute the property of being to the left of whoever occupies the objectively specified location to its North-West with the respective objectively specified orientation. But it does not amount to the property of being to the left of $u$ s (understood in first-personal terms). This is reflected in the more general fact that egocentric space cannot be fully specified in objective terms - which is why the two are to be distinguished in the first place. In particular, what we describe with the expression 'to our left' is not a cardinal direction in objective space (Campbell 1995). ${ }^{23}$

Without this lack of strict correlation between egocentric and objective spatial features, it would also seem impossible to explain why we cannot suffer an illusion with respect to perceiving something as being to our actual left. Of course, when facing South, we may perceive a building as being to our actual left while, in fact, it is located to the SouthWest of our current location in objective space. But, as the previous considerations have indicated, the objective orientational properties of the building are neither sufficient, nor necessary for its instantiation of any subjective orientational property. What happens in cases like this is just that we fail to track the former by perceiving the latter - an error which is due to some breakdown in our relation to our environment. ${ }^{24}$

But the subjectivity of egocentric orientations has consequences for our attempts to visualise objects as having them. Objects can possess these subjective features only when they are perceived as having them. Furthermore, this is true as much of imagined or other possible situations, as it is true of actual ones - assuming that they all contain the same ontological kind of objects and properties. Finally, the dependence in question does not range over different possible worlds, but is confined to a single one: the perceived object and the perception are always part of the same world. Hence, visualising an object as having such an experience-dependent property requires imagining a suitable perception of that object. Visualising a building as being to the left, for instance, has to involve imagining a perception of a building as being to the left.

\section{Responding to intentionalist responses}

It should now be easier to understand why some of the objections raised against Martin's considerations in support of thesis (ii) have in fact been missing their target. In many 
cases, this is due to the fact that the critics have overlooked or underappreciated the importance of subjectivity in Martin's line of thought. A good example for this is Tyler Burge's discussion of Martin's argument for (ii). Burge seems to have no problem to accept that visualising an object as being to the left requires the presence of a respective point of view in the imagined situation. But he rejects the claim that there also has to be a perception which occupies this location:

[Martin] begins by rightly noting that visualizing an object involves taking an imagined visual perspective on the object - for example, visualizing it from a perspective according to which the object is to the left. [...] Martin assumes that since the perspective is from some position in the imagined scene, it must be the perspective of an imagined experience in the imagined scene, or of an experience imagined to be in the imagined scene. This seems tantamount to begging the question in an argument for the Dependency Thesis. (Burge 2005, 63ff.)

But it is not clear whether Burge's charge really is one of begging the question. For he still seems to briefly discuss - and dismiss - Martin's argument involving the subjective perspectivalness of our presentation of orientational features. Here is how the first part of the passage just quoted continues:

It is quite true that one could have such a perspective on the object only if one were to have an experience of the object. It does not follow that if one imagines something from a perspective that one could have only if such and such were the case (only if one were experiencing the object from that perspective), then in imagining something from that perspective one must imagine such and such to be the case. (Burge 2005, 63)

One problem with this passage is to understand the difference between 'having a perspective on an object' and 'imagining something from that perspective'. That Burge takes the two to be different becomes evident in his claim that only the first requires having a perceptual experience of the object. So what does 'having such a perspective on an object' mean? If what is meant is simply visually presenting an object as being to the left, without further specifying whether this presentation is perceptual or imaginative, then the intended contrast collapses. For visualising an object to the left involves such a presentation, too. Furthermore, since Burge wants to deny that visualising requires imagining a perception, his claim that 'having such a perspective' requires having a perceptual experience turns out to be false. So this cannot be the right interpretation of his words. If, on the other hand, what is meant by 'having such a perspective' is visually perceiving an object as being to the left, then we get the desired contrast, given that visualising something does not involve perceiving it. But then, the noted dependence claim becomes trivial and has nothing to do with subjectivity. Perceiving an object as being to the left obviously requires having a perception of it. And it does so independently of the subjective status of the perspectivalness or the perceived properties involved. So, if this reading is correct, Burge does not really engage with Martin's focus on the subjective element in our perceptions of egocentric orientations.

Something similar seems to happen in Paul Noordhof's direct reply to Martin's paper. ${ }^{25}$ For example, he acknowledges that the Dependency Thesis is plausible - if not true - in the case of subjective properties. But he does not recognise that this is how the egocentric properties figuring in Martin's examples should probably be understood. Moreover, he does not properly address the fact that what really matters in Martin's main argument is not the ontological status of the perceived properties, but instead that of our perspective onto them. 
This has, for instance, the result that he underestimates the resources of proponents of the universal truth of the Dependency Thesis (among whom he seems to count Martin) for explaining the apparent fact that we find this thesis more plausible in some cases than in others:

As I have already noted, the Dependency Thesis varies in plausibility depending upon the sensory modality we consider. It is more plausible when we consider what is involved in imagining the feel of somebody's skin or the taste of bacon. Our capacity to imagine these things seems to rest upon our capacity to imagine our experiences of these things. The proponent of the Dependency Thesis needs to explain why it is more plausible in these cases given that the Dependency Thesis holds across the board. My guess is that the proponent of the Dependency Thesis might try to argue that the variation in plausibility depends upon contingent psychological facts about what we find easier to consider independent of experience. The issue is whether we should search for an explanation there rather than in the objects and properties imagined. If the feel of someone's skin or the taste of bacon imply the existence of corresponding perceptual experiences in contrast with other objects of imagination, then the Dependency Thesis cannot be true for all sensory imaginings. (Noordhof 2002, 446)

Here, Noordhof insists that the perceived difference in plausibility should be explained in terms of a difference in the objects and properties imagined. His suggestion is that we find it plausible with respect to certain things, but not others, to conceive of imagining them as an instance of experiential imagination because we understand that they, but not the other things, involve some experience-dependent element. So Noordhof, too, proposes a limitation of the Dependency Thesis to cases pertaining to subjectivity. But he fails to acknowledge that this is exactly Martin's non-universalist take on the issue. Besides, Martin can explain the difference between instances of imagining which require experiential imagination and instances which do not without having to refer to contingent facts about what we find easy to conceive of as being experience-independent. For he can simply refer to the involvement of subjective aspects of character - such as the perspectivalness involved in the perception of egocentric orientation.

A very similar oversight becomes apparent in Noordhof's discussion of the factors which determine what is imagined when we are visualising something. Although he does not draw this connection, it will be helpful to briefly consider the elements involved in fixing what is part of the situation depicted by a painting. The marks on the surface (plus perhaps our general recognitional abilities) determine whether the painting depicts a blonde man or a brunette woman. But assuming that it is a blonde man, extra-pictorial factors - such as the stipulation of a title or the exploitation of iconographic conventions - decide whether it is a portrait of, say, Saint John or Hercules. The pictorial element puts certain constraints on the extra-pictorial take on the nature of the depicted entities, which cannot be overridden by the latter. An artist may turn his painting of a man into a portrait of Jean of Arc by labelling it as such. But it will then be a painting of Jean of Arc in the disguise of a man.

Noordhof's observation is that very similar factors are responsible for determining the nature of the objects of visualising. On the one hand, there is the basic visual presentation and, on the other hand, the accompanying intentions or suppositions which put a certain conceptual gloss on that visual presentation. To take an example from Peacocke (1985), when we are visualising a suitcase, we may think of it as a suitcase with a cat hidden behind it, or as a suitcase which is merely hallucinated by some brain in a vat. The visual presentation is limited to the presentation of the suitcase, while the wider imaginative project concerns also other aspects of the imagined situation. And again, how we conceive 
of the visualised entities as part of such a project is constrained by how these entities are visually given to us. We may use the visual presentation of the suitcase in order to imagine a car, but only by imagining a car with the visual appearance of a suitcase. ${ }^{26}$

According to Noordhof, this constraint on what is imagined as part of the wider imaginative project is problematic for a proponent of the Dependency Thesis. His starting point is the idea that it is possible to pursue the project of imagining a certain object, and nothing else. The subject engaged in this project conceives of it in terms of the object, but not in terms of any experience of that object. Hence, if the project is also taken to involve imagining an experience of the object, this cannot be due to any of the accompanying intentions or suppositions of the subject. So a proponent of the Dependency Thesis has to assume that the imagining of the experience is part of the visual presentation of the object. But this seems to violate the constraint of the visual presentation on the extra-visual interpretation of it. For we cannot pursue the project of imagining nothing but an object by means of an episode of visualising which involves imagining more than that object. The only way out appears to be to consider the extra-visual gloss on the visual presentation to be irrelevant or, even worse, misleading:

When we consider what characterises an imaginative project, it is clear that there are cases where the project is to imagine merely an $F$. Proponents of the Dependency Thesis don't have to resist this but, if they don't, they must insist that certain facts about the mental image override a subject's own characterisation of his or her imaginative project so that, in fact, what is imagined is a perceptual experience of an $F$. This is quite a strong claim to have to establish. (Noordhof 2002, 430)

The questionable assumption in Noordhof's line of reasoning, however, is that imagining an object as having a certain feature is always distinct from, and more basic than, imagining perceiving such an object. For this is not true if that feature is the egocentric orientation of an object. Visualising such an orientation requires the involvement, but not the instantiation, of a perception-dependent phenomenal aspect (e.g. that of leftishness); and what is thereby visualised is, presumably, a subjective state of affairs. Imagining the instantiation of an egocentric orientation therefore involves imagining a perception of that instantiation. As a consequence, it is a misconception to think that it is possible to imagine 'merely' such a feature, if this is meant to exclude imagining an experience of it. Notably, when we describe an episode of ours simply as one of imagining an object as being to the left, our characterisation is at best incomplete. It may refer to the episode of imagining a perception of an object as being to the left. Or it may denote the episode of imagining an object as being to the left of a specific perceiver - which has to include explicitly imagining that perceiving subject in addition to the object. But contrary to what Noordhof suggests, there is no simpler episode of imagining to be picked out by that description. Much the same response should be given to Burge's insistence that it is natural and not incoherent to say that we can visualise something without imagining experiencing it: ${ }^{27}$

It seems to me that in a certain clear and natural sense, one can visualize an object and not imagine visually experiencing the object. One imagines the object from the perspective of a visual experience, but no experiencing of the object (either by oneself or by anyone else) is imagined to be included in the imagined scene. [...] Prima facie, there seems to be nothing contradictory in this claim, as there would be if (DT') [i.e. (ii)] were (constitutively) true. (Burge $2005,63)$

Again, the problems start once we focus on visualising orientational features that locate objects in egocentric space. Their imagination requires the imagination of a perceptual 
perspective onto them. That it is still natural for us to say that what we are imagining is just the object and its orientation may suggest that we either make use of an elliptical characterisation, or have no full grasp of the nature of our episode of imagining and, in particular, of the subjectivity involved in the perspectival presentation of egocentric orientations. Indeed, it is to be expected that not all of our conceptions of subjective properties characterise them as subjective. For example, we can discover that the phenomenal aspect of leftishness and the property of being to our actual left are in fact experience-dependent. So we should be able to conceive of those properties without conceiving of them as subjective. But this means that we can engage in imagining without fully grasping what we are thereby engaging in. In particular, we may imagine an instance of a specific egocentric orientation without realising that we are thereby imagining a perception of it.

This helps to resolve another of Noordhof's worries. Granting his opponent, for the sake of argument, that imagining perceiving something constitutes sometimes the most basic episode of imagining available to us, he still insists that it has to involve an - explicit or implicit - thought which conceives of what one is imagining in terms of an experience. But that visualising is therefore supposed to require the possession of the concept of an experience casts doubt on whether, say, children under the age of four can visualise something, given that they may lack the notion of an experience.

If the Dependency Thesis rests on the claim that imaginers, at least tacitly, suppose that they are imagining a perceptual experience, then it links the capacity to imagine with possession of the concept of perceptual experience. In which case, the attribution of imaginings to the autistic, young children, and animals, becomes as doubtful as their possession of the concept of perceptual experience. (Noordhof 2002, 436)

While acknowledging that the evidence seems undecided on this last issue, Noordhof is right in pointing out that this connection to the empirical question of when children acquire the concept of experience threatens to undermine the Dependency Thesis. For not only does it seem empirically far less controversial whether young children can visualise something than whether they can conceive of perceptions. But the issue of when children become able to conceive of experiences should not be expected to have such a strong bearing on the issue addressed by the Dependency Thesis - namely the constitution (if not the concept) of imaginative experience.

These problems related to an over-intellectualisation of visualising arise, however, only if the Dependency Thesis indeed implies that imagining perceiving something requires the possession or application of the concept of perception. Noordhof assumes that it does. But the proponent of the Dependency Thesis need not - and should not - follow him in this. As already noted, we need not fully grasp the nature of our imagining when being engaged in it. And this includes the fact that it may involve imagining an experience. But, more importantly, this partial ignorance is possible because we imagine an experience, not by thinking of it as part of the imagined situation, but by experientially imagining the instantiation of its character. That is, imagining an experience is a form of object awareness, and not of thinking. What the Dependence Thesis - in the form of thesis (ii) - claims is that the visual presentation involved in relevant cases of visualising consists in the experiential presentation of the character of a visual perception. And this kind of object awareness does not involve the employment of the concept of a visual perception. At best, it relies on some discriminatory or recognitional capacities with respect to experiences, as well as perhaps some basic demonstrative ways of referring to the respective experiences as 'this' or 'that'. It is of course still possible for us to add some additional thoughts to our episode of experiential imagination. For instance, we can take the imagined experience to be a hallucination, or one of the 
perceptions that Napoleon had when looking at the battle of Jena. But the basic form of imagining a perception does not involve such conceptualisations, but instead constrains them.

The final intentionalist criticism that I would like to address is the charge that understanding visualising in terms of imagining and perceiving raises more questions than that it answers. It is worthwhile to note that, if this charge is adequate, it poses a general difficulty for all views, assuming that the argument concerning the visualisation of egocentric orientations goes through. But it is true that more needs to be said about the nature of experiential imagination and, in particular, how it can accommodate certain important features of visualising - notably its involvement of a visual, perspectival and nonneutral presentation of external things. Part of this explanatory challenge can be restated by the distinction between the exemplification and the representation of a subjective aspect of character. Episodes of seeing exemplify a perceptual character, while episodes of visualising - if they amount to experiential imagination - involve the imaginative representation of such a character. What then needs explaining is how the proposed kind of representation can ensure that the character of representing (i.e. that of visualising) is very similar to the represented character (i.e. that of seeing) in the mentioned respects (i.e. visual presentation, perspectivalness and non-neutrality), without being identical to it.

In addition to the problems just mentioned, there is obscurity in the explanation provided by the Dependency Thesis. It rests upon the idea that the experience is represented in imagination. But it is unclear how to cash this out. [...] It is hard not to think that all the explanatory work is being done by the nature of imagination and the kind of representation which serves it. (Noordhof 2002, 447)

Noordhof is absolutely right about the last point. But the proposed kind of representation is perhaps less mysterious than it might seem to him and others. Consider the reproduction of a painting - for instance, a postcard hanging at your wall. This image does not itself amount to a painting and differs substantially from one (e.g. it does not involve paint and has no perceivable texture). But it nonetheless inherits important aspects of the reproduced painting. Most of all, it depicts the same objects and features, and from the same perspective, as the painting. Indeed, if the reproduction is done well, its perspectivalness derives from that of the reproduced painting, and not from the perspectivalness of the photographic process involved in the reproduction. That is, the impact of the point of view occupied by the lens directed at the painting is typically negligible in comparison with the impact of the point of view inherent to the photographed depiction. ${ }^{28}$ Much more can surely be said about how the reproduction does end up presenting the same situation from the same perspective as the painting. But the absence of such further elucidations does not render the kind of representation involved in photographic reproduction mysterious or completely unilluminating. We accept that this kind of representation exists. And the description given above gives us some grasp of what it amounts to. In fact, we know at least that the reproduction represents the painting partly by representing the visual perspective of the painting; and that it represents the latter's perspective by presenting the same objects and features as they are presented to the point of view of the painting.

Imagining a perception involves the same kind of representation. It represents a perception partly by representing the latter's perspective. And it does this by presenting the same external objects and features as they are presented to the point of view of such a perception. In imagining a perception, we thus imagine a possible perceptual perspective onto the world. ${ }^{29}$ And, as in the case of the reproduction of a painting, the resulting episode of visualising ends up with a character very similar in its visual, perspectival and non-neutral character to that of an episode of seeing. Besides, we also know that this imaginative 
representation of a perceptual perspective constitutes an experiential form of object awareness, which may be spelled out in intentional terms - an idea which, incidentally, disjunctivists agree with. Although it leaves many issues open, this characterisation of what experiential imagining amounts to, and how it can inherit some of the features of the imagined experiences, should be illuminating enough to rebut the charge of obscurity. The proposed kind of representation is involved in other phenomena as well. And we have some understanding of how it can explain the presence of the important features of reproductions and episodes of visualising noted.

To illustrate that explanatory power, it is worthwhile to have a brief look at how this account of experiential imagination can answer a challenge raised by Currie and Ravenscroft $(2003,28) .{ }^{30}$ They ask for an account of why it is possible that we may mistake an instance of seeing for an instance of visualising (e.g. as in Perky's experiments), and that we may recall something as seen that we have merely visualised in the past (e.g. as in the case of fabricated memories). Their suspicion is that the defenders of the Dependency Thesis do not have the resources to identify the underlying similarities, assuming that they have to accept a difference between what we see and what we visualise as part of the respective experiences.

How could we explain, on this hypothesis, why people are prone to misrecall visualizing as seeing, and in some circumstances will mistake perception for visualization? According to the hypothesis, visualizing an $F$ has the representational content, not $F$, but seeing an $F$. Thus the seeing and visualizing have quite different contents. Why would states with such different contents seem to us to be so similar? Content is just one dimension of similarity; perhaps states could differ in content and be similar in other ways. But the hypothesis offers us no account of what these other similarities might be and how they could, in the face of content-dissimilarity, sustain the overall phenomenological similarity that seeing and visualizing enjoy. (Currie and Ravenscroft 2003, 28)

One part of the answer to this challenge is to stress that, for a proponent of the Dependency Thesis, there is - contrary to what Currie and Ravenscroft suggest - a substantial overlap in content between seeing and visualising. For imagining a perception of an external object involves the visual presentation of that object as part of the imagined situation - just as the reproduction depicts whatever is depicted by the reproduced painting. In other words, experiential imagination has two objects: the imagined experience and the external thing presented by the latter. We have already seen how disjunctivism can accommodate this fact by taking the imagination of a perception to consist in the imagination of the instantiation of a relational character with two relata. I will address the issue of how experiential intentionalism can allow for more than one object of experiential imagination at the end of the next and final section of this paper. The other part of the reply to Currie's and Ravenscroft's challenge is that, as already illustrated by reference to the analogy with the reproduction of paintings, the presentation of external things involved in imaginatively adopting the subjective perspective of a perception shares many important aspects with the presentation of those things involved in perceiving them from such a perspective. Accordingly, seeing and imagining seeing resemble each other, not only in what they make us aware of, but also in how they present it to us.

\section{Meeting the challenge for intentionalism}

There are good reasons to accept the first two members of the inconsistent triad introduced at the beginning. So why should - and typically do - intentionalists accept the third? What 
forces them to assume that imagining a visual perception of an external thing is neutral about the latter's presence in the imagined situation? To answer this question, it will actually be helpful to have a look at why disjunctivists reject this thesis.

What we are concerned with are cases in which we visualise an external object by imagining a perception of it. And we imagine a perception by experientially imagining the instantiation of the character of a perception. According to disjunctivism, the character of a perception - and therefore the perception itself - is partly constituted by the perceived object. So what we are doing when we are imagining a perception is that we are imagining a relational character. And this involves imagining the two relata: a subjective perspective and the external things and features presented to that perspective. ${ }^{31}$ In other words, by experientially imagining a perception, we imagine all its experiential constituents which include the perceived object, since the latter constitutes part of the character of the perception. So, in some sense, such instances of experiential imagination take two objects: the perception and the perceived object. But since the former is relational in character by containing the latter, we in fact imagine a single, but complex object, namely the perception.

This account can easily explain the transparency and non-neutrality of visualising. Visualising consists, partly, of the representation of external things and their features, given that it consists of the representation of a character constituted by those entities. And in line with the intentionalist nature of that representation, the character of visualising is partly determined by what it represents. Hence, when we reflect on the character of an episode of visualising, we are bound to find the represented objects and features as part of what is visualised. Moreover, we do not find any other candidate objects of awareness. There are no internal pictures or similar entities involved in visualising. And the subjective perspective, which constitutes the imagined perception as its second relatum, is not given as an object of awareness, but rather as part of the subject of awareness. This means, of course, that introspection reveals not only what we are aware of, but also the way in which we are aware of it. So a strong representationalist interpretation of transparency and the character of visual experience (Dretske 1995; Tye 1995; Speaks 2009) is not compatible with the resulting picture. But strong representationalism is undermined, in any case, by the fact that seeing and visualising can have the same external things and features as objects, so that their difference in character has to be due to some other element, namely the kind of object awareness involved.

The intentionalist treatment of imagining perceiving differs from the one just presented because intentionalism does not assume that the perceived object constitutes the character of the perception. But, as Martin has noted, this fact gives rise to a problem (Martin 2003, sect. 4). Both parties in the debate agree that, when we are imagining an object, we are nonneutral about the presence in the imagined situation of what we are imagining. Hence, in imagining a perception, we are committed to the presence of a perception - or, more specifically, the instantiation of a perceptual character - in the imagined world. However, according to intentionalism, the presence of a perception does not entail the presence of a perceived object. For perception is, from an experiential point of view, an experience of exactly the same kind as a hallucination: they both possess the same intentional character. But this means that there is no difference between imagining a perception and imagining a hallucination. In both cases, we imagine the same perceptual character. And since the instantiation of this character does not involve any external things, we imagine it without imagining such things. However, if we do not imagine an external thing as part of imagining a perception, there is no reason to assume that the latter is non-neutral about the presence of an external thing in the imagined situation. After all, this kind of 
non-neutrality comes with imagining something and seems to extend just to what is imagined. This argument of Martin may be summarised as follows (see especially Martin $(2003,415 \mathrm{ff})$.$) :$

(iii.1) Imagining an object is non-neutral about the presence of that object - including its constitutive parts - in the imagined situation; and about no other object's presence.

(iii.2) The object of awareness in the case of imagining a perception of an external thing is the perception.

(iii.3) Perceptions do not involve any external things as constituents.

(iii) Hence, imagining a perception of an external thing is neutral about the latter's presence in the imagined situation.

The disjunctivist can block this argument by rejecting (iii.3), but it is far less obvious how the intentionalist could avoid having to accept its conclusion. The premisses (iii.1) and (iii.3) seem to be simply part of the intentionalist outlook on things. That perceiving is intentional just means that it does not involve the perceived object as its element. And, more generally, intentional presentations are committal insofar as they involve a respective attitude towards the presented. Accordingly, the non-neutrality of imagining should extend just to what is imagined. Premiss (iii.2), on the other hand, simply states a definitional truth about part of what the imaginative object awareness of a perception amounts to. However, if the intentionalists have to accept (iii), they have to reject (i) or (ii). And, as the previous sections were meant to show, neither is a feasible option. So what has to go, it seems, is intentionalism itself - and at least (iii.3) with it.

It does not help to highlight the fact that, according to intentionalism, imagining a perception involves imagining a commitment towards the presence of an external thing in the imagined world. As described in the first section, intentionalists claim that perceptions involve an intentional attitude towards their objects which takes the latter to be present in the situation before the perceiving subject. In the case of an imagined perception, this non-neutrality concerns of course the presence of the object in the imagined world, which also contains that perception and the related imagined subjective perspective. Imagining a perception therefore involves imagining taking an external thing to be part of the respective situation. But imagining such a commitment is compatible with actually staying neutral on the issue. Hence, this aspect of experiential imagination does not suffice to establish the non-neutrality of actual instances of visualising (cf. Martin 2003, 415).

Now, that intentionalists indeed endorse the problematic claim (iii), and roughly for the reasons sketched, may be illustrated by reference to Burge's discussion of Martin's paper. Once it is assumed that it is sometimes possible (if not even necessary) to visualise an object by imagining perceiving it - an assumption which he is happy to grant - Burge seems to have no problem with any of the three premisses needed to derive thesis (iii). ${ }^{32}$ In particular, he is clear about the fact that the intentionalist view takes perceptions not to involve their objects (cf. (iii.3)). And he also assumes that imagining a perception does not itself involve imagining an external thing to be present in the imagined situation (cf. (iii.1) and its discussion in the second section). Instead, this presence is merely supposed as part of a thought accompanying or even preceding the imagining of the perceptual experience. Burge's complaint is, in fact, that Martin is wrong in demanding that the commitment about the presence of the visualised object in the imagined situation should be part of the experiential imagination. 
The 'intentional theory' is not required to explain how by merely imagining an experience with a certain representational content one thereby supposes that the content is veridical. I deny that this supposed explanandum is even true. In the imagined experience which, according to the Dependency Thesis, is involved in visualizing, one does not take the representational content of the imagined experience itself to involve or entail the presence of the visualized object. Rather one has begun with the supposition of veridicality. One simply takes the content of the imagined experience to be veridical. The content itself might not have been veridical. That is the position of the 'intentionalist theory'. Certainly, it is my position. (Burge $2005,65)$

As discussed in the second section, what Burge is rejecting here is thesis (i). But he is happy, as an intentionalist, to embrace thesis (iii) - and thereby opens up his position to Martin's criticism. For the non-neutrality involved in visualising cannot simply be moved from the episode of visualising to the additional supposition. The transparency and non-neutrality of visualising are aspects of the kind of object awareness involved in visualising (cf. claim (i)). And this kind of object awareness is, according to the Dependency Thesis, identical with an instance of experientially imagining a perception (cf. (ii)). Hence, it is already part of the experiential imagination that an external thing is given as part of the imagined situation. And, together with thesis (iii), this leads to an inconsistent position.

However, as I would like to suggest in the remainder of this paper, intentionalism need not endorse thesis (iii) and thus may answer the challenge put forward in Martin's paper. The key thought is that intentionalists need not endorse premiss (iii.1) in its current form. They should agree that imagining something is non-neutral towards what is imagined. But they should also point out that there are other ways in which imagining - or at least imagining a perception - can be committal. A closer look at the intentionalist understanding of the commitment involved in visual experience will show how this is possible.

According to intentionalism, the commitment to the presence of some visually perceived or imagined object in the respective situation is compatible with there being no such object. For instance, when we hallucinate a green tree, we are non-neutral about the existence of a green tree in our actual environment, despite there being no such tree there before us. The committal aspect of perceptual experiences is therefore independent of the presence or absence of a perceived object. ${ }^{33}$

The same is true of the non-neutrality involved in visualising. It is plausible to maintain that, as the default case (i.e. in the absence of intentions or suppositions to the opposite effect), visualising an object suffices for the presence of that object in the imagined world. After all, specific imagined situations are populated by those possible (and perhaps impossible) entities which we imagine to be part of them. But this is a fact about the nature of imagined worlds, and not about the nature of imaginative commitment. The principle at work here is something like that imagined worlds are such that they contain whichever entities our imaginings are non-neutral about. This principle assumes that imaginings are committal, but it does not exploit any aspect of the nature of that commitment. That is, its truth does not depend on what it means for imaginative experiences or thoughts to be non-neutral. Hence, nothing speaks against this non-neutrality being independent of the presence or absence of an imagined object.

This object-independence, however, leaves room for the possibility of an imaginative commitment which is not due to the constitution of the imagined perception by its object. But what else could be the source for such a commitment? The answer can perhaps a bit surprisingly - in fact be found in the disjunctivist rejection of premiss (iii.3). One factor that is central in this rebuttal is that disjunctivism distinguishes sharply 
between imagining a perception and imagining a perception-like hallucination. They are two different imaginative projects. Imagining a perception consists of imagining the instantiation of a perceptual character. The problem with imagining a hallucination is that, according to disjunctivism, we do not know anything positive about the character of such an experience. We know merely that its character is subjectively indistinguishable from that of a perception. Hence, the only way for us to imagine a hallucination is to imagine the instantiation of a perceptual character and then simply to stipulate that the resulting imagined experience is a hallucination which only seems to exemplify a perceptual character, but in fact exemplifies a character which is indistinguishable from a perceptual one.

One thing that is very important to note about this is that the two imaginative projects do not differ in which character is imagined as being instantiated. They differ only in that one is the most basic - or default - case of imagining a perceptual experience, while the other requires some additional suppositions. The other thing not to be missed is that this already suffices to ensure that imagining a perception is non-neutral about the presence of an external thing in the imagined situation - reference to the constitution of perceptions is not needed. That imagining a perception is the default case when we are trying to imagine a perceptual experience means, among other things, that imagining a hallucination requires explicitly denouncing the perceptual status of the imagined experience. But this is possible only if imagining a perception is non-neutral about its being a perception (whatever that means for its constitution). Hence, visualising an external thing - that is, imagining a perception of such a thing - comes, by default, with a commitment to the presence of a visual perception (rather than a hallucination) in the imagined situation. But perceptions differ from hallucinations in being factive (again, independently of the constitution of either). Accordingly, the presence of a perception implies the presence of a perceived object. So the commitment involved in visualising extends to the presence of an external thing in the imagined world. And its double source is the factivity of perceptions and the default status of imagining a perception.

What is crucial now is that an intentionalist can adopt more or less the same account of the two different projects. The only difference is that the character to be imagined in both imaginative projects counts as perceptual for a different reason. Disjunctivism maintains that this character is perceptual because only perceptions, but not hallucinations, possess it. By contrast, intentionalists accept that this character is shared by perceptions and perception-like hallucinations. Nonetheless, intentionalists can still count it as perceptual, and not as hallucinatory, because it is characteristic of perceptions, and not of hallucinations. This has the consequence that imagining the instantiation of this character amounts, by default, to imagining a perception (rather than a hallucination). Nothing more is needed, especially no intention or thought concerning the perceptual status of the imagined experience. Imagining a hallucination, on the other hand, involves not only the experiential imagination of that character, but also a supposition to the effect that the imagined experience is hallucinatory, despite first appearances. The rest of the intentionalist story is the same as the disjunctivist one. That imagining a perception is the default case means, partly, that imagining the character in question comes with a commitment to the presence of a perception in the imagined situation. And this non-neutrality extends again to the visualised external things and features because of the factivity of perception. 
It still has been left open, of course, why - and in which sense - the character shared by perceptions and some hallucinations is characteristic of the former, but not of the latter. One aspect of this is that being a perception implies having this character, while being a hallucination does not. For not all hallucinations are subjectively indistinguishable from perceptions and therefore do not share the same character (Dorsch 2010b). But the more important (and related) element is that the character in question involves a self-reflexive form of intentionality which is concerned with the presentation of the respective experiences as perceptions (and not as hallucinations). As already noted in the first section, perceptions and first-personally indistinguishable hallucinations differ in their third-personally accessible structure which may or may not relate them to the world. The thought is now that it is part of their common intentionality that perceptions and hallucinations present not only the world, but also themselves as being a certain way. More specifically, both kinds of perceptual experience present themselves as relating us to external things in the manner distinctive of perceptions. This presentational aspect forms part of their shared character. But only perceptions do actually relate us in the relevant way to external things and therefore present themselves adequately. By contrast, hallucinations are not relational and thus mislead us about their own third-personal structure (Dorsch 2010a; Dorsch and Soldati forthcoming). The character of perceptual experiences is thus characteristic of perceptions, and not hallucinations, because it subjectively marks both of them as perceptions, and not hallucinations. Their shared character is characteristic of perceptions, and not hallucinations, because it adequately reflects the structure of the former, but not of the latter.

The character of perceptual experiences is not unlike the appearance of real and fake lemons. The latter two are (ideally) visually indistinguishable because they share the same appearance. But this appearance is characteristic of real lemons, and not of fake lemons. When we see an object with that appearance, we take it, by default, to be a real lemon. And visualising an object with that appearance amounts, by default, to visualising a real lemon. In this case, the priority of real lemons over fake lemons is, of course, grounded in very different factors - such as their value for us, their natural or artificial status or perhaps even their sheer number. But the basic phenomenon is the same: we have some form of object awareness (experiential $v s$. visual), and the respective presentational element or appearance is, by default, non-neutral about what is presented. Besides, in both cases, the difference between the default experience and its non-default counterpart is that the latter involves an additional thought concerned with the further specification or re-characterisation of what is presented. We do not, say, first see an object with a lemonlike appearance and then judge it to be that of a real lemon, rather than a fake one; we simply see a lemon. Similarly, imagining the instantiation of a character characteristic of a perception suffices to count as imagining a perception; no additional stipulation that the imagined experience is a perception, and not a hallucination, is needed. 
The proposed version of intentionalism - experiential intentionalism - departs significantly from those which are currently more orthodox (see footnote 2 for references). In particular, it differs from them in agreeing with disjunctivism that the priority of perceptions over perceptual-like hallucinations is not exhausted by the fact that both kinds of perceptual experience involve a perceptual attitude, that is, take their objects to actually exist and to be as they present them as being. It is also said to include the fact that hallucinations possess a perceptual character and present themselves as perceptions; and not vice versa. As a result, hallucinations and their features (e.g. their motivational and rational powers) have to be elucidated in terms of perceptions and their characteristic character; while the latter can be discussed without any reference to hallucinations. ${ }^{34}$ The claim that the self-presentational character of perceptual experiences adequately reflects the structure of perceptions and therefore counts as characteristic of perceptions may perhaps require the assumption that the underlying structural difference between seeing and hallucinating is one in nature. That is, experiential intentionalism should perhaps be combined with structural disjunctivism (as defined in the first section). This would, for instance, be more in line with phenomenal disjunctivism insofar as then both this view and experiential intentionalism would account for the difference between imagining a perception and imagining a hallucination - which obtains despite both projects involving imagining the instantiation of one and the same character - partly in terms of a difference in nature in what is imagined. But either way is fine: experiential intentionalism is compatible with structural disjunctivism, but does not require it. ${ }^{35}$

\section{An objection to disjunctivism}

There are independent reasons for preferring the intentionalism put forward here over its intentionalist rivals - and, indeed, over disjunctivism. For instance, the proposed view promises to be able to capture both externalist and internalist epistemological ideas: it can identify the third-personal, relational structure of perceptions as their knowledgerelevant and reason-giving features, while also ensuring some first-personal, experiential access to them which does not suffer the problem over-intellectualisation (Dorsch 2010a; Dorsch and Soldati forthcoming). Here is, however, not the space to elaborate on this and other advantages of the view; or to discuss how it may respond to some of the other challenges directed at intentionalism (e.g. those raised in Martin (2004)). Instead, I would like, in closing, to formulate an objection to the disjunctivist account of the transparency and non-neutrality of visualising.

Disjunctivism has objected to intentionalism that the latter cannot properly account for the commitment involved in experientially imagining a perception. In the preceding section, I have argued that this objection can be met by intentionalism in the form of experiential intentionalism. My contention now is that disjunctivism cannot properly account for the commitment involved in experientially imagining a hallucination. Disjunctivism assumes that we experientially imagine a perception-like hallucination by experientially imagining the instantiation of a perceptual character and by additionally supposing that what is indeed is imagined is an experience which possesses a different, but subjectively indistinguishable character.

[W] hen one takes on the project of sensorily imagining visual hallucination as opposed to visual perception, what one has to do is imagine the situation as for the perceptual situation. One's appreciation of its hallucinatory status will not come from some phenomenologically distinctive element of what one has imagined, but rather the further cognitive gloss one puts on it all. That is, when one sensorily imagines a visual hallucination, one puts oneself in a position where one takes the imagined situation to contain the objects presented, and then uses that image as the basis of imagining a situation just like it in which it appears to one as if there is such an object, although none is present. (Martin 2003, 417) 
The main problem with this proposal is that the presence in the imagined situation of an external thing, which is a consequence of the presence of the imagined relational perception, cannot be properly cancelled out by the additional supposition that there is no such thing present in the imagined situation, after all. As a result, it - wrongly - turns out to be impossible to experientially imagine a perception-like hallucination. For the disjunctivist, a perception and its character is constituted by its object; and imagining the former involves imagining the latter. Hence, imagining a perceptual character includes imagining a perceived object as part of the imagined world. Now, once the suggested supposition is added, the question arises of whether this basic episode of experiential imagination still suffices for the presence of the external object in the imagined situation. If the answer is yes - and assuming that the presence of this object is a determinate matter - the opposing supposition can, in this respect, have no impact on what the imagined world contains.

This means, however, that we continue to imagine a perception and thus have not really succeeded in imagining a hallucination. But it is surely possible for us to succeed in pursuing the latter project.

So the answer to the question has to be no: the experiential imagination of the perception does not any more determine that the imagined situation contains an external thing. But this has the consequence that it also cannot any more determine that this situation contains a perceptual experience. It cannot posit a perception as part of the imagined world because this would, after all, require positing an external thing. And it cannot posit a hallucination because this would require imagining the character of hallucination, and not that of a perception. Hence, the experiential imagination stops altogether to determine what the imagined world contains, once the supposition is added. And the hallucination is therefore only intellectually imagined to be part of the imagined situation, but not experientially. Again, we have failed in our project, which was to experientially imagine a hallucination. In short, disjunctivism entails the impossibility of experientially imagining a perceptionlike hallucination. The underlying reason for this is, of course, that disjunctivists should deny that we have any access to the positive nature of the character of such a hallucination (Martin 2004; Dorsch 2010a). We merely know that it is indistinguishable from the character of a perception. But this knowledge does not suffice to imagine the instantiation of the character of a perception-like hallucination. The difficulty with this is that we seem nonetheless to be able to experientially imagine having such a hallucination. The disjunctivist cannot account for this possibility.

Experiential intentionalism, as well as other versions of intentionalism, do not face the same problem. The character of a perception-like hallucination is, after all, identical with that of a perception. And we can experientially imagine its instantiation because we have positive knowledge of its nature - especially its intentional nature. The same is true of visualising fake lemons. We know positively what they look like, namely that they have the same appearance as real lemons. And we can therefore visualise them, even if this requires some additional stipulation that we are not confronted with the default case. This cancelling out is not problematic in the case of imagining a hallucination, since the experiential imagination of the respective character can loose its power to ensure the presence of an external thing, without loosing its power to ensure the presence of a perceptual experience. For no constitutive link is assumed to hold between the character of perceptions and their objects. 
It seems therefore better to give up this constitutive claim - and thus disjunctivism and to locate the source of the transparency and non-neutrality of both seeing and visualising in the factivity of perceptions and their priority over hallucinations. Does this mean that visualising an external thing - in cases where it is identical with imagining a perception does not really involve visually imagining such a thing? Is the imagined perception the only object of the experiential imagination potentially involved in visualising? The answer should, of course, be no: visualising an external thing makes us visually aware of it and is not neutral towards its presence in the imagined situation. This is possible because experiential imagination takes two objects. These objects are of different kinds (experiences $v s$. external things). They are presented in different ways (experientially or phenomenally $v s$. visually, auditorily, etc.). And they may or may not be independent of each other (e.g. in the case of an imagined pain, they are not). So what intentionalists should do is to add a clause about the other object of experiential imagination to premiss (iii.2):

(iii. $2^{*}$ ) The objects of awareness in the case of imagining a perception of an external thing are the perception and the external thing.

\section{Acknowledgements}

That the two objects are given to us in a different way is also apparent in the fact that we are aware of one of them (i.e. the external thing) solely by being aware of the other (i.e. the perception of it). This is also exactly what happens in the case of a reproduction of a painting: the former represents what the latter depicts by representing the latter. And in the case of both experiential imagination and the reproduction of an artwork, what is represented the character of a perception and a painting, respectively - is not relational, that is, not constituted by the objects that they themselves present. This doubling of objects does not undermine the transparency of visualising or, more generally, experiential imagination. For while the imagined experiences are objects of awareness, they are not given to us as objects of awareness. Instead, we are aware of them by imaginatively adopting the subjective perspective inherent to them. Nonetheless, they still count as genuine objects of awareness because our episodes of experiential imagination are non-neutral about their presence in the imagined world.

I thank Malcolm Budd, Peter Goldie, Rob Hopkins, Mike Martin, Kevin Mulligan, Matt Nudds, Gianfranco Soldati, Matt Soteriou, Juan Suarez and the members of the philosophy research colloquium at the University of Fribourg for many beneficial discussions about intentionalism and disjunctivism. In addition, I am very grateful to two anonymous referees and the editor of this symposium, Marcus Willaschek. My work on this article was generously supported - in the form of a Fellowship for Advanced Researchers - by the Swiss National Science Foundation (grant no. PA00P1-126157).

\section{Notes}

1. See, especially Martin (2003, 417ff.). McDowell (1998) and Fish (2009) defend versions of disjunctivism, which - in many relevant respects - come close to that defended by Martin and discussed here.

2. See Dorsch (2010a), as well as Dorsch and Soldati (forthcoming), for more detailed discussions of these differences. Among the current proponents of intentionalism, which have written explicitly on visualising and experiential imagination, are Hopkins (1998), Noordhof (2002), Currie and Ravenscroft (2003) and Burge (2005). Others are Dretske (1995), Tye (1995) and Speaks (2009). 
3. I use the term 'experience' to denote not only sense experiences, but all instances of conscious object awareness, including episodes of visualising and of experiential imagination. The expression 'perceptual experience' is meant to cover both (veridical) perceptions and hallucinations, and I distinguish between the latter two independently of whether they differ in nature or not. Besides, when I speak of 'hallucinations', I mean to refer, if not stated otherwise, to perception-like hallucinations - that is, hallucinations which are subjectively indistinguishable from perceptions (Dorsch 2010a).

4. See Martin's distinction between the semantic and the stative conception of representation in Martin (2003).

5. The resulting characterisation of intentionalism is meant to be neutral between its various versions, including both naturalistic and non-naturalistic conceptions of its nature. That is, the first-personal presentational and attitudinal aspects of perceptions may - but need not be - further elucidated in terms of mental representation and functional role. In Dorsch and Soldati (forthcoming), we argue that at least reference to representation is not very helpful, since it ignores the essential connection between intentionality and consciousness or subjectivity. A similar issue with functional role is whether it is the same as rational role, or whether it is non-normative in nature. If the latter, we again contend that intentionality cannot be separated from normativity.

6. This conclusion is not necessitated, since perceptions and hallucinations might possibly differ in aspects of character that are not linked to how they make us aware of objects and features. But it is not clear what aspects that could be, or why it should be plausible to assume their existence.

7. This difference is sometimes also spelled out in terms of perceptions 'acquaintaining' us with things, or making them 'manifest' to us (though intentionalists can presumably adopt at least the first manner of talking). Besides, it can be ignored here what disjunctivists do, or should, say about hallucinations and their subjective indistinguishability from perceptions. It is perhaps defensible to argue that they still make us intentionally aware of objects (Smith 2002). But it seems more natural for disjunctivism to conclude that hallucinations do not make us aware of objects at all - they just seem to do so.

8. Indeed, it may very well be that the transparency at issue is, in fact, inseparably linked to the presentation of objects, rather than the entertainment of propositions. When introspecting experiences, the external things that we find are shown to us; and no internal objects are given to us in this way. The issue of whether a given thought is transparent in this sense does not arise then, since thinking is not an instance of object awareness.

9. Martin (2003, 37 and 39) mentions the example of mentally rotating a piece of furniture in a shop in order to see whether it is possible to get it through one's front door at home.

10. The claim may become trivial, if it can be established that object awareness is, by its very presentational nature, transparent and commital (see footnote 8). But to establish this is not a trivial task.

11. Note that Martin uses 'experience' here as short for 'sense experience', such as perception or bodily sensation. As already mentioned, my own use is less narrow in also including, say, visualising or other imaginative instances of object awareness.

12. A further possible locus of misunderstanding is perhaps that (ii) understands both visualising and imagining a perception as instances of object awareness, given that some intentionalists tend to construe visual experience in terms of thought-like contents (see, for instance, Dretske (1995) and Tye (1995)).

13. It is true, though, that others - such as Peacocke (1985) and O'Shaughnessy (2003) - have put forward stronger versions of the claim, extending even to all kinds of sensory imagining. And Martin is clearly sympathetic with this more general conclusion, as can be witnessed in Martin (2003, 404ff.) and Martin (2001).

14. See section 3 in Martin (2003), which is mostly occupied with the development of his argument in favour of thesis (ii), the restricted version of the Dependency Thesis. In what follows, I draw heavily on this section of Martin's paper. I am also very grateful to the challenging questions about this section raised by Marcus Willaschek, which helped me greatly to get clearer about certain details of Martin's argument, as well as about my own addition to it at the end of this section. 
15. It does not really matter for Martin's main argument whether we are concerned here with two different sets of spatial properties of objects (e.g. one objective, and the other subjective), or instead with two modes of presentation of one and the same set. What is relevant here is primarily the fact that our perceptual access to spatially located objects is perspectival and, in particular, presents them as orientated towards us, rather than in more objective terms. But many of the points involved in the argument can be described more easily by reference to egocentric properties. Besides, the postulation of subjective orientations is not much different from the postulation of subjective modes of presentation (cf. the similar issue raised below with respect to the aspect of leftishness and similar phenomenal aspects).

16. In what follows, I concentrate on the fact that perceptions present objects in actual space and mention the temporal dimension only when it becomes relevant.

17. It should become clear very shortly that there is a third possibility: the experience may represent another experience as instantiating or presenting the quality.

18. Using the expression 'being to the left' to denote a monadic property is not ideal, since this expression clearly has some connotations of relationality. But it is not easy to come up with another formulation, without altogether loosing the connection to the perceived property of being to our actual left. I am grateful to Marcus Willaschek for making me aware of this issue.

19. Very similar issues arise, for instance, with respect to the status of the quality of ovalness another perspectival aspect of perception - which figures in our experience when we are looking at objects from an angle and perceive them as round. Again, we typically draw round objects by tracing elliptical shapes on the canvas. But it is debatable whether our experiences present round objects as elliptical in addition to presenting them as round (see, for instance, Peacocke's (1983) discussion of what he calls sensational properties). One significant difference from egocentric orientation is, however, that, while roundness is an objective property, being to the left of us is not.

20. Of course, Martin cannot assume in his argument that an experience's instantiation of the aspect of leftishness is also sufficient for the existence of something to our actual left. This would follow only if the experience is a perception, and if perceptions are always factive - something that intentionalists deny.

21. There is also the issue of whether visualising always locates objects relative to us, rather than to some imagined subject. The default case seems to be that we visualise objects as orientated towards ourselves, and that imaginative projects involving subjects different from us require the additional identification of our imagined point of view with that of those other subjects (Wollheim 1984; Martin 2003, 411).

22. The possibility of experiencing a phantom limbs as hurting is no exception. The only difference is that, in this case, the existence of the hurting body part is subjective as well. But, in any case, nothing here depends on whether the presented view on pains and pain experiences is correct. The analogy is merely meant to further illustrate Martin's treatment of the involvement of subjective elements in imaginative experience.

23. Compare also the famous example of two incongruent hands with different orientations in Kant (1992).

24. The property of being to our left shares both discussed aspects with the property of being here if ascribed to ourselves. The latter, too, cannot be specified in purely objective terms. And we cannot go wrong in being aware of ourselves as being here. One difference between our awareness of us as being here and our awareness of other objects as being to our left is, however, that the latter may concern hallucinated objects. This is not problematic for the present argument since it relies only on the claim that the instantiation of egocentric orientations requires the occurrence of a perception of them, but not on the reverse claim. Besides, as already suggested in note 22 , there are perhaps other ways of reconciling the subjectivity of a property with the possibility of hallucinating an instance of it. 
25. Currie and Ravenscroft $(2003,28)$ also do not address the issue of subjectivity when they briefly sketch Martin's motivation for endorsing thesis (ii).

26. See also Peacocke's (1985) discussion of Wittgenstein's example of King's College on fire.

27. See also the similar point against the Dependency Thesis made by Currie and Ravenscroft (2003, 27ff.).

28. The process of photo-copying, which does not involve any such perspective onto the reproduced piece of paper, is perhaps an even better illustration of the kind of representation pertaining to experiential imagination (as proposed by Martin in a personal discussion about how best to understand Hume's Copy Principle).

29. This idea is not new. In particular, Hume's Copy Principle may be read as claiming pretty much the same if applied to the case of imagining.

30. Reference to the kind of representation at issue promises also to illuminate why episodes of visualising often possess a lesser degree of repleteness, determinacy or intensity than episodes of seeing. Just as the reproduction of a painting may lead to the loss of some of these qualities, imagining perceiving something may have this effect. Martin's employment - in Martin (2001) - of the Dependency Thesis in his account of the phenomenological differences between seeing, visually remembering and visualising provides another example of the explanatory force of treating at least some instances of visualising as an instance of experiential imagination.

31. It is interesting to ask to which extent imagining a subjective perspective involves imagining a subject. It seems that we need not be in any way specific about the identity of such a subject when visualising - although we may also be very specific in the form of additional suppositions (Martin 2003, 411).

32. He does not explicitly comment on how to characterise experiential imagination. But there is no reason to suspect that he would reject premiss (iii.2).

33. Again, this is false for disjunctivism, according to which perception-like hallucinations are non-commital because of their lack of any presentational elements. This means, among other things, that the intentionalist proposal of an object-independent non-neutrality of perceptions cannot be used to argue against the disjunctivist view that the non-neutrality of perceptions is due to their being constituted by their objects (and, indeed, vice versa). What we have here are two rival accounts of perceptual commitment, which are so far diactically on a par. The last section of the paper is meant to change the balance concerning this issue in favour of intentionalism.

34. See Martin $(2003,2004)$ and Dorsch (2010a). Similar ideas can be found in the intentionalist views inspired by the phenomenological tradition, such as that put forward in Smith (2002).

35.

But see the end of Dorsch (2010a) for a line of reasoning which supports the supplementation of experiential intentionalism with structural disjunctivism. 


\section{References}

Burge, T. 2005. Disjunctivism and perceptual psychology. Philosophical Topics 33: 1-78.

Campbell, J. 1995. Past, space and self. Cambridge, MA: MIT Press.

Currie, G., and I. Ravenscroft. 2003. The recreative mind: Imaginations in philosophy and psychology. Oxford: Oxford University Press.

Dorsch, F. 2010a. Experience and introspection. In Hallucination, ed. F. Macpherson and D. Platchias. Cambridge, MA: MIT Press.

Dorsch, F. 2010b. The unity of hallucinations. Phenomenology and the Cognitive Sciences 9, no. 2: $171-91$.

Dorsch, F., and G. Soldati. Forthcoming. Intentionalism, experiential and phenomenal error.

Dretske, F. 1995. Naturalizing the mind. Cambridge, MA: MIT Press.

Fish, W. 2009. Perception, hallucination, and illusion. Oxford: Oxford University Press.

Hopkins, R. 1998. Picture, image and experience. Cambridge: Cambridge University Press.

Kant, I. 1992. Concerning the ultimate ground of the differentiation of directions in space. In The Cambridge edition of the works of Immanuel Kant. Theoretical philosophy: 1755-1770, ed. David Walford and Ralf Meerbote, 365-72. Cambridge: Cambridge University Press.

Martin, M.G.F. 2001. Out of the past: Episodic recall as retained acquaintance. In Time and memory, ed. C. Hoerl and T. McCormack, 257-84. Oxford: Oxford University Press.

Martin, M.G.F. 2003. The transparency of experience. Mind and Language 4, no. 4: 376-425.

Martin, M. 2004. The limits of self-awareness. Philosophical Studies 120, no. 1-3: 37-89.

McDowell, J. 1998. Mind and world. Cambridge, MA: Harvard University Press.

Noordhof, P. 2002. Imagining objects and imagining experiences. Mind and Language 17, no. 4: 426-55.

O'Shaughnessy, B. 2003. Consciousness and the world. Oxford: Oxford University Press.

Peacocke, C. 1983. Sense and content: Experience, thought, and their relations. Oxford: Oxford University Press.

Peacocke, C. 1985. Imagination, experience and possibility. In Essays on Berkeley, ed. H. Robinson and J. Foster, 19-35. Oxford: Clarendon Press.

Sartre, J.P. 2004. The imaginary: A phenomenological psychology of the imagination. London: Routledge.

Smith, A.D. 2002. The problem of perception. Cambridge, MA: Harvard University Press.

Speaks, J. 2009. Transparency, intentionalism, and the nature of perceptual content. Philosophy and Phenomenological Research 79, no. 3: 539-73.

Tye, M. 1995. Ten problems of consciousness. Cambridge, MA: MIT Press.

Williamson, T. 2008. The philosophy of philosophy. Oxford: Blackwell.

Wittgenstein, L. 1984. Zettel. Frankfurt: Suhrkamp.

Wollheim, R. 1984. The thread of life. Yale: Yale University Press. 